\title{
Tokat’tan Yeni Bir Lignikol Mantar Kaydı: Lachnum subvirgineum Baral
}

\author{
Hakan IŞIK ${ }^{1}$, İbrahim TÜRKEKUL2 ${ }^{2}$ iD \\ ${ }^{1}$ Tokat Bilim ve Sanat Merkezi, Tokat, ${ }^{2}$ Gaziosmanpaşa Üniversitesi, Fen-Edebiyat Fakültesi, Biyoloji Bölümü, Tokat \\ $\square$ : hakanbiyoloji@gmail.com
}

\section{ÖZET}

Bu çalışmada, Lachnum subvirgineum Baral, Türkiye mikotası için ilk kez kaydedildi. Yeni kaydın kısa deskripsiyonu, fotoğrafları, bazı ekolojik özellikleri ve tartışması verilmiştir.
DOI:10.18016/ksudobil.336129

Makale Tarihçesi

Geliş Tarihi : 25.08.2017

Kabul tarihi : 16.04.2018

Anahtar Kelimeler
Biyoçeşitlilik,
Makrofungus,
Yeni kayıt,
Tokat,
Türkiye

Araştırma Makalesi

\section{Lachnum subvirgineum Baral: A new lignicolous fungus record from Tokat}

\section{ABSTRACT}

In this study, Lachnum subvirgineum Baral was recorded for the first time for Turkish mycota. Short description of the new record, illustrations, some ecological features and discussion are provided.

\section{Article History}

Received : 25.08.2017

Accepted : 16.04.2018

\section{Keywords \\ Biodiversity, \\ Macrofungi, \\ New record, \\ Tokat, \\ Turkey}

\section{Research Article}

To Cite : Işık H, Türkekul İ 2018. Tokat’tan Yeni Bir Lignikol Mantar Kaydı: Lachnum subvirgineum Baral. KSÜ Tarim ve Doğa Derg 21(4):555-558, 2018. DOI:10.18016/ksudobil.336129

\section{GiRiş}

Mantarlar, dünyada en fazla çeşitliliğe sahip organizmalardandır. Klorofil taşımayan, absorbsiyon ile beslenen, spor ile çoğalan mantarlar, gıda, ilaç, biyokontrol faktörleri, farmasötik ve diğer birçok endüstride kullanılan biyoaktif bileşiklerin kimyasal üreticileri oldukları için ekonomik açıdan önemlidir. Ascomycota ve Basidiomycota bölümlerinde bulunan makrofunguslar ekolojik olarak saprofitler, parazitler ve simbiyotik (mikorizal) türler olmak üzere üç gruba ayrılabilir. Yaklaşı 70 bin mantar türünün tanımı literatürlere girmesine rağmen doğada 1.5 milyon türün bulunduğu tahmin edilmektedir (Hawksworth ve ark., 1996; Andrew ve ark., 2013; Kinge ve ark., 2017 ).
Ülkemizin mantar çeşitliliğini belirleme konusunda yapılan çalışmalar artarak devam etmektedir. Sesli ve Denchev (2014)'e göre Türkiye mikotası için 2158 makrofungus kaydı yapılmıştır. Bunların 215'i ascomycota ve 1943 'ü basidiomycota bölümlerine aittir. Son yıllarda yapılan çalışmalarla; (Uzun ve ark., 2015; Kaya ve ark., 2015; Sesli ve ark., 2015; Kaya ve Uzun 2015; Sesli ve Moreau, 2015; Akata ve Doğan, 2015; Akata ve ark., 2016a; Akata ve ark., 2016b; Sesli ve ark., 2016; Acar ve ark., 2016; Doğan ve ark. 2016; Taşkın ve ark., 2016a; Taşkın ve ark., 2016b; Türkekul ve Işık, 2016; Işık ve Türkekul, 2017; Türkekul, 2017; Kaya ve ark., 2017; Sesli ve Topcu Sesli A, 2017) bu sayı giderek artmaktadır. 
Lachnum cinsi, dünya çapında yaklaşık 467 takson ile temsil edilen büyük bir gruptur (Kirk P., 2011; URL). Bitki kalıntıları (otsu bitkilerin ölü gövdeleri, ağaç veya çalıların dalları) üzerinde saprofit olarak yaşayan bu cins küçük, sapsız veya kısa saplı, dış yüzeyi tüylerle kaplı, ektal eksipulumu prizmatik hücreli bir apotezyuma sahip olması ile karakteristiktir. Apotezyumun iç kısmı beyaz, sarı, turuncu, kırmızımsı veya kahverengi olabilir. Tüyler beyaz veya kahverengi, silindirik, septalı ve küçük granüllerle kaplanmıştır. Askus tipik olarak konik uç kısma sahiptir ve apikal sporlar genellikle Melzer ayıracı ile maviye boyanır. Parafiz lanseolattır ve askustan daha uzundur (Dimitrova, 2000; Whitton ve ark., 2012; Beug ve ark. 2014). Çalışmamızın amacı Türkiye mikotasına katkıda bulunmaktır.

\section{MATERYAL ve YÖNTEM}

Çalışma materyali olan makrofungus örnekleri, TokatSivas karayolu üzerinde bulunan çam ormanından 2017 ilkbaharında toplanmıştır. Makrofungusun doğal habitatında fotoğrafı alınarak, morfolojik ve ekolojik özellikleri kaydedilmiş, koleksiyon numarası verilmiştir. Toplanan örnekler laboratuvar ortamına getirilerek mikroskobik özellikleri ortaya çıkarılmıştır. Makroskobik ve mikroskobik özellikleri ortaya çıkarılan mantarların teşhisi ilgili literatür; Breitenbach ve Kränzlin (1984), Jordan (1995), Beug ve ark. (2014), Suková (2005), Ribes (2009) kullanılarak yapılmıştır. Teşhisi yapılan mantar örnekleri Gaziosmanpaşa Üniversitesi Fen-Edebiyat Fakültesi Biyoloji Bölümü Fungaryumu'nda saklanmaktadır.

\section{BULGULAR}

Yeni kayit makrofungusun deskripsiyonu, apotesyumun, askusun, parafizin ve sporların mikrofotoğrafları, lokalitesi ve koleksiyon numarası aşağıda verilmiştir. Makrofungusun sistematiği http://www.indexfungorum.org (erişim tarihi: 19.11.2017)'e göre yapılmıştır.

\section{Fungi}

\section{Ascomycota}

Lachnaceae

Lachnum subvirgineum Baral, in Baral \& Krieglsteiner, Beih. Z. Mykol. 6: 83 (1985).

Apotesyum 0.45-1.35 mm çapında, beyaz renkli, kuruduğunda hafif kahverengidir (Şekil 1a). Tüyler siğilli, kapitat ve daha az siklıkta silindirik şekilli, çoğunlukla 5 septalı, 65-95 × 5.4-6.1 $\mu \mathrm{m}$ (Şekil 1d). Askuslar operkulat, 44-54 × 4-4.5 $\mu \mathrm{m}$ (Şekil 1c). Askosporlar fusiform, 6-9 x 1.5-1.8 $\mu \mathrm{m}$ (Şekil 1b). Parafizler lanseolat, 50-70 × 3.5-4.2 $\mu \mathrm{m}$.

Incelenen materyal: Tokat-Sivas karayolu, çam ormanı, Pinus nigra J.F. Arnold kozalağı üzerinde bulunmuştur. 07.05.2017, 40¹2' 533" K, 36 30' 031" D, 1183 m, ISIK 699.

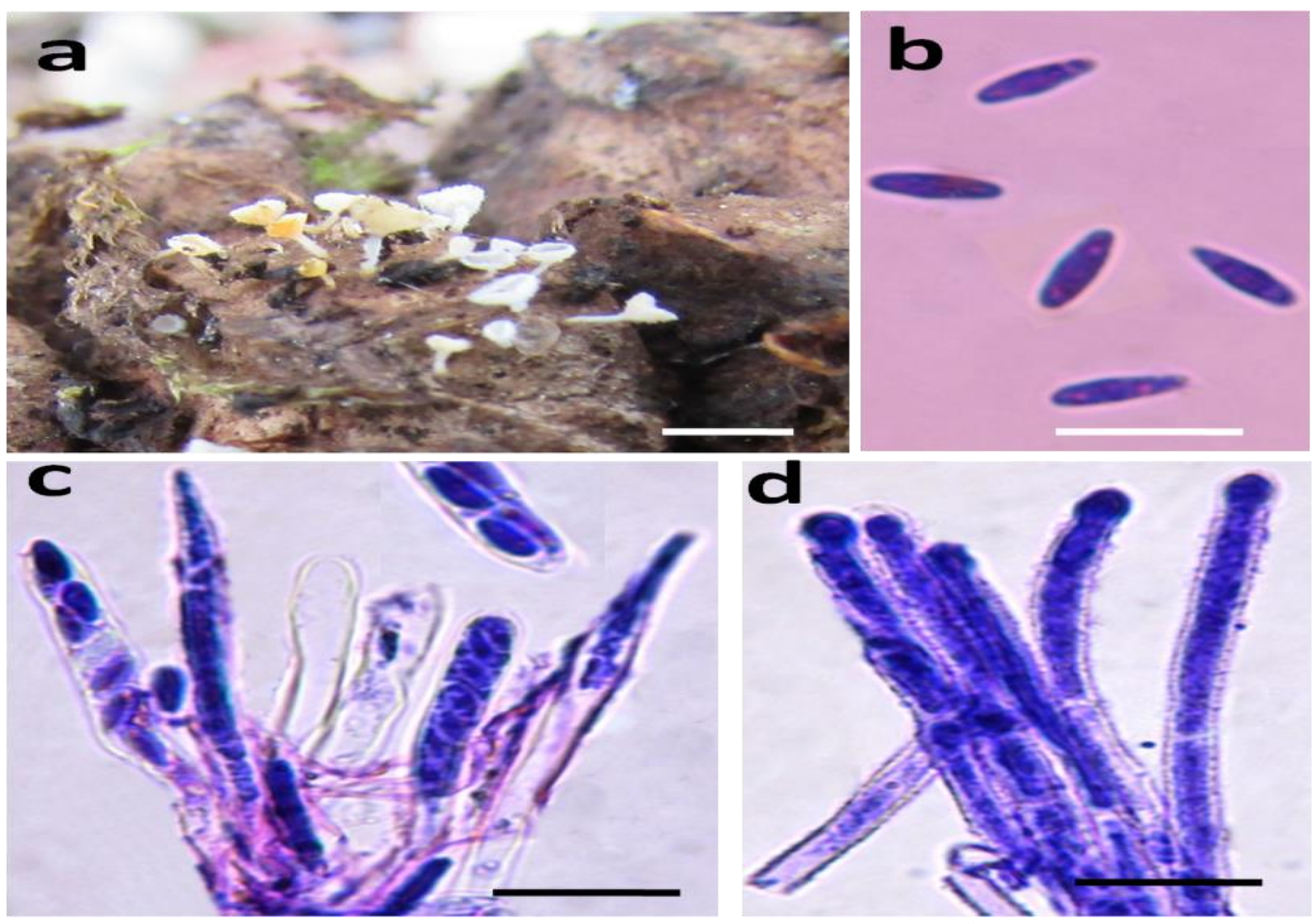

Şekil 1. Lachnum subvirgineum: a- askokarplar, b- askosporlar (Laktofenol), c- askus ve parafizler (Laktofenol), $\mathrm{d}$ - tüyler (Laktofenol) (ölçek çubuğu: $\mathrm{a}=3 \mathrm{~mm}$; b,c ve d= $10 \mu \mathrm{m}$ ) 


\section{TARTIŞMA ve SONUÇ}

Yapılan bu çalışma ile Lachnum subvirgineum Baral Türkiye mikotası için ilk defa rapor edilmiştir. Ülkemizden Lachnum cinsine ait 7 tür bildirilmesine rağmen bu türlerden bazıları (L. barbatum (Kunze ex Fr.) J. Schröt., L. cerinum (Pers.) Morgan,) başka gruplara aktarılmıştır. Böylece geçerli tür sayısı 5'e düşmüştür. Bu türler L. brevipilosum Baral, L. bicolor (Bull.) P. Karst., L. corticale (Pers.) Nannf., $L$. pygmaeum (Fr.) Bres., L. virgineum (Batsch) P. Karst. şeklindedir (Sümer, 1982; Aktaş ve ark., 2006; Öztürk ve ark., 2010; Kirk, 2011; Sesli ve Denchev, 2014; Akata ve ark., 2014). L. virgineum (Batsch) P. Karst. apotesyumun özellikleri, parfizin genişliği, askus ve askosporun boyutu ve tüylerin uzunluğu gibi morfolojik özellikler bakımından L. subvirgineum'a benzemektedir. Ancak L. subvirgineum'un tüyleri daha kisadir (L. subvirgineum : (54-)65-95 x (4.3-)5.4$6.1 \mu \mathrm{m}$; L. virgineum: 70-120(-160) x 3.7-4.6 $\mu \mathrm{m})$ ve tüylerin apikal kısımları bariz olarak geniştir. L. subvirgineum'un apotesyumları L. virgineum'a göre daha büyüktür (Suková, 2005). Ülkemizde tespit edilen diğer benzer Lachnum türü L. pygmaeum (Fr.) Bres.'dur. L. pygmaeum, uzun sapl apotesyumlara, daha uzun tüylere ve daha kısa askusa sahiptir (Suková, 2005). L. brevipilosum Baral'un tüyleri daha kısadır $(45-60 \mu \mathrm{m})$ ve biraz daha büyük silindirikklavat sporlara sahiptir $(8-9 \times 3-3.5 \mu \mathrm{m})$ (Ribes, 2009). L. bicolor (Bull.) P. Karst. Apotesyumu yumurta sarısıturuncu sarı renktedir ve daha uzun tüylere sahiptir $(130-200 \times 4 \mu \mathrm{m}) \quad($ Beug ve ark., 2014). L. corticale (Pers.) Nannf. Apotesyumu soluk sarı renkte ve soluk bej-kahverengi tüylerle kaplıdır. Tüyler L. subvirgineum'a göre daha uzundur (120-185 $\times 3.5-4 \mu \mathrm{m})$ ve daha büyük septalı sporlara sahiptir (Dimitrova, 2000; Breitenbach ve Kränzlin, 1984 ).

\section{KAYNAKLAR}

Acar İ, Demirel K, Ömeroğlu Boztepe G 2016. Lice (Diyarbakır) Yöresi Makrofungusları. Mantar Dergisi, 7(1): 29-39.

Akata I, Kaya A, Uzun Y 2014. Two New Lachnum Records for Turkish Mycobiota. Journal of Applied Biological Sciences, 8(1): 28-30.

Akata I, Doğan HH 2015. Orbiliaceae for Turkish Ascomycota: Three New Records. Bangladesh J. Bot., 44(1): 91-95.

Akata I, Uzun Y, Kaya A 2016a. Macrofungal diversity of Zigana Mountain (Gümüşhane/Turkey). Biological Diversity and Conservation, 9(2): 57-69.

Akata I, Kabaktepe Ş, Akgül H, 2016b. Cordyceps militaris, The First Record From Family Cordycipitaceae in Turkey. Kastamonu Uni., Orman Fakültesi Dergisi, 16 (1): 280-284.

Aktaş S, Kaşık G, Doğan HH, Öztürk C 2006. Two new taxa records for the macrofungi of Turkey. Turkish Journal of Botany, 30: 209-212.
Andrew EE, Kinge TR,Tabi EM, Thiobal N, Mih AM 2013. Diversity and distribution of macrofungi (mushrooms) in the Mount Cameroon Region. Journal of Ecology and the Natural Environment, 5(10): 318-334.

Breitenbach J, Kränzlin F 1984. Fungi of Switzerland, Volumes 1. Verlag Mykologia, Luzern, İsviçre, $359 \mathrm{p}$.

Beug MW, Bessette AE, Bessette AR 2014. Ascomycete Fungi of North America. Austin, TX, University of Texas Press, USA, 488p.

Dimitrova E 2000. A taxonomic study of Hyaloscyphaceae in Bulgaria. II. Dasyscyphus, Lachnum, Trichopezizella. Phytologia Balcanica, 6(1): 133-145.

Doğan HH, Bozok F, Taşkın H, Büyükalaca S 2016. Türkiye İçin Beş Yeni Morchella Kaydı. Alatarım, 15 (1): 1-11.

Hawksworth DL, Kirk PM, Sutton BC, Pegler DN 1996. Ainsworth and Bisby's Dictionary of the Fungi, 8th edition. CAB International, Wallingford, United Kingdom, 632p.

Işık H, Türkekul İ 2017. A new record for Turkish mycota from Akdağmadeni (Yozgat) province: Russula decolorans (Fr.) Fr. Epicr.. Anatolian Journal of Botany, 1(1): 1-3.

Jordan M 1995. The Encyclopedia of Fungi of Britain and Europe. Frances Lincoln, London, 384p.

Kaya A, Uzun Y, Karacan İH, Kaya ÖF, Yakar S 2015. Macromycetes determined in Islahiye (Gaziantep/Turkey) district. Biological Diversity and Conservation, 8(3): 209-217.

Kaya A, Uzun Y 2015. Six new genus records for Turkish Pezizales from Gaziantep Province. Turkish Journal of Botany, 39: 506-511.

Kaya A, Uzun Y, Karacan IH, Yakar S 2017. New additions to Turkish Hyaloscyphaceae. Mantar Dergisi, 8(1): 13-19.

Kinge TR, Apalah NA, Nji TM, Acha AN, Mih AM 2017. Species Richness and Traditional Knowledge of Macrofungi (Mushrooms) in the Awing Forest Reserve and Communities, Northwest Region, Cameroon. Journal of Mycology, 2017(1): 1-9.

Kirk P 2011. Index Fungorum. URL: http://www.indexfungorum.org (erişim tarihi: 19.11.2017).

Öztürk Ö, Doğan HH, Yıldırımlı Ş 2010. Macrofungi of Eldivan dağ (Çankırı). The Herb Journal of Systematic Botany, 17(2): 141-154.

Ribes M Á 2009. Contribution to the mycobiota knowledge from Canary Islands (Spain) I. Bol. Soc. Micol. Madrid 33: 201-223.

Sesli E, Denchev CM 2014. Checklists of the myxomycetes, larger ascomycetes, and larger basidiomycetes in Turkey. 6 th. Mycotaxon Checklists Online: 1-136.

Sesli E, Vizzini A, Contu M 2015. Lyophyllum turcicum (Agaricomycetes: Lyophyllaceae), a new 
species from Turkey. Turkish Journal of Botany, 39: 512-519.

Sesli E, Moreau PA 2015. Taxonomic studies on some new fungal records from Trabzon, Turkey. Turkish Journal of Botany, 39: 857-866.

Sesli E, Türkekul I, Akata I, Niskanen T 2016. New records of Basidiomycota from Trabzon, Tokat, and İstanbul provinces in Turkey. Turkish Journal of Botany, 40: 531-545.

Sesli E, Topcu Sesli A, 2017. Infundibulicybe alkaliviolascens (Tricholomataceae): Türkiye Mikotası için Yeni Bir Kayıt. Mantar Dergisi, 8(1): 6-12.

Suková M 2005. A revision of selected material of lignicolous Lachnum species from the Czech Republic with a note on graminicolous material of the Lachnum pygmaeum complex. Czech Mycology, 57(3-4): 183-219.

Sümer S 1982. Batı Karadeniz Bölgesi, özellikle Bolu çevresinde Bulunan Odun Tahripçisi Mantarlar. İstanbul Üniversitesi Orman Fakültesi Yayınları, 297-312.
Taşkın H, Doğan HH, Büyükalaca S 2016a. Morchella galilaea, an autumn species from Turkey. Mycotaxon, 130: 215-221.

Tașkın H, Doğan HH, Büyükalaca S, Clowez P, Moreau PA, O’Donnell K 2016b. Four new morel (Morchella) species in the elata subclade (M. sect. Distantes) from Turkey. Mycotaxon, 131: 462-482.

Türkekul İ, Işık H 2016. Contribution to the macrofungal diversity of Yozgat Province (Turkey). Mycotaxon, 131: 483.

Türkekul İ 2017. New Calbovista, Mycena, Rhizopogon, Stictis and Symphyosirinia records from Turkey. Mycotaxon, 132(3): 503-512.

URL: (http://www.mycobank.org. erişim tarihi: 19.11.2017).

Uzun Y, Acar İ, Demirel K, Keleş A 2015. Macrofungal diversity of Hani (Diyarbakır/Turkey) district. Biological Diversity and Conservation, 8(1): 28-34.

Whitton SR, McKenzie EHC, Hyde KD 2012. Fungi associated with Pandanaceae. Springer, Netherlands, 458p. 